\title{
Conflitos em Unidades de Conservação na Amazônia: o caso do Parque Estadual Monte Alegre - Pará
}

\section{Conflicts in conservation units in the Amazon: the case of the state park of Monte Alegre}

Irabel Cavalcanti Ibiapina Parente - Socióloga, antropóloga e mestre em Desenvolvimento Sustentável pelo Centro de Desenvolvimento Sustentável pela Universidade de Brasília. Pesquisadora da Rede Clima - Mudanças Climáticas e Desenvolvimento Regional. E-mail: izabelcip@gmail.com

Marcel Bursðtyn - Socioeconomista, doutor em Desenvolvimento Econômico e Social, professor associado no Centro de Desenvolvimento Sustentável da Universidade de Brasília. E-mail: marcel. cds@gmail.com

\section{Resumo}

A criação de Unidades de Conservação de Proteção integral tem impactado de diversas formas as populações localizadas no interior ou no entorno de áreas protegidas. $\mathrm{O}$ foco deste artigo é o Parque Estadual Monte Alegre (PEMA), localizado na porção noroeste do Pará. Criado em 2001, com objetivo principal de proteger as pinturas rupestres da área, o PEMA é um exemplo típico dos conflitos advindos da criação de UCs na região amazônica. As restrições ao uso da terra impostas pela criação do PEMA provocam mudanças nas práticas produtivas e na própria dinâmica das comunidades afetadas, gerando tensões e frustrações. Este artigo analisa os conflitos, a partir de estudo junto a comunidades locais. $\mathrm{O}$ entendimento do problema pode servir de referência a decisões sobre a criação de outras áreas protegidas na região, reduzindo-se os focos de tensão.

\section{Palavras-chave}

Conflitos. Áreas protegidas. Ribeirinhos. Pinturas rupestres. Parque Estadual Monte Alegre, Brasil, Amazônia.

\begin{abstract}
The creation of conservation units has impacted in many ways the populations located inside or around protected areas. The focus of this article is the State Park of Monte Alegre (Parque Estadual Monte Alegre - PEMA), located in the northwestern portion of Pará, Brazil. Created in 2001 with the main objective of protecting the cave paintings of the area, PEMA is a typical example of conflicts arising from the creation of protected areas in the Amazon region. Restrictions on land use imposed by the creation of PEMA cause changes in production practices of the communities, generating tensions. This article examines the conflict involving local communities. The understanding of the problem can serve as a reference for decisions on the creation of other protected areas in the region, reducing sources of tension.
\end{abstract}

\section{Keywords}

Conflicts. Protected areas. Riparian communities. Cave paintings. Parque stadual Monte Alegre, Amazon. 


\section{INTRODUÇÃO}

A Amazônia desperta o imaginário dos observadores e visitantes por sua extensão, exuberância e riquezas naturais. Além do gigantesco manancial de água doce, a floresta amazônica possui um enorme potencial de aproveitamento econômico, seja na produção de fármacos e cosméticos, seja na extração de minerais, de recursos madeireiros e de tantos outros produtos. No entanto, desde a chegada do colonizador europeu, um traço em comum marca a penetração na floresta amazônica: a destruição do ambiente natural. O desmatamento da floresta e a consequente perda de biodiversidade suscitam pressões internacionais e nacionais pela proteção da floresta e criação de unidades de conservação (UCs) na Amazônia.

O modelo de UC adotado no Brasil deriva da concepção de áreas protegidas surgida nos Estados Unidos, em meados do século XIX. A criação das áreas protegidas tem como pressuposto principal proteger a vida selvagem ameaçada pelo avanço da civilização urbano-industrial. Este modelo fundamentase na ideia de que a alteração e domesticação de toda biosfera pelo ser humano é inevitável, sendo necessário e possível conservar pedaços do mundo natural em seu estado originário, livres da intervenção humana.

As UCs criadas segundo esse modelo são, muitas vezes, resultado de um processo arbitrário de tomada de decisões, cujos atores partem da suposição de que os remanescentes florestais e animais estariam acima do direito de uso das coletividades que moram nos seus limites territoriais. Passadas algumas décadas desde o surgimento das primeiras UCs no Brasil ${ }^{1}$, fica evidente a questão: como compatibilizar os propósitos de conservação ambiental segundo a fórmula de áreas de exclusão de uso, com a garantia do acesso às populações locais, que nem sempre são ameaçadoras à integridade de tais ambientes?

No Brasil, são inúmeros os conflitos provocados pela criação de áreas protegidas. Os conflitos em UCs são mais acentuados em áreas de proteção integral. Estas admitem apenas o uso indireto dos atributos naturais, isto é, não admite consumo, coleta, dano ou destruição dos recursos naturais. Os residentes da área devem ser indenizados e devidamente realocados pelo Poder Público (Lei no 9.985/2000). A expulsão e/ou confinamento de populações em pequenas áreas no entorno de UCs geram conflitos entre moradores do local e instituições dedicadas à gestão da UC.

O foco deste estudo são os parques (uma das categorias de UCs estabelecidas pela Lei do SNUC, de 18 de julho de 2000), mais especificamente

\footnotetext{
Os primeiros parques brasileiros surgiram na década de 1930: Itatiaia, criado em 1937, e Iguaçu e Serra dos Órgãos, criados em 1939.
} 
o Parque Estadual Monte Alegre (PEMA), no estado do Pará, Brasil. Criado em novembro de 2001, o PEMA apresenta, além da beleza cênica, aspectos geomorfológicos e arqueológicos que justificaram a sua criação. No entanto, a criação do PEMA provocou conflitos entre o órgão responsável pela proteção da área (Secretaria de Estado de Meio Ambiente - SEMA/PA) e as comunidades ribeirinhas de Lages, Paituna e Santana, situadas no interior e nas imediações do PEMA.

O objetivo deste artigo é analisar os conflitos envolvendo populações ribeirinhas, provocados pelas restrições ao uso dos recursos naturais impostas pela criação do PEMA. Para atingir esse objetivo, além da pesquisa bibliográfica e documental, realizou-se pesquisa de campo no Pará (municípios de Belém, Santarém e Monte Alegre), em agosto e setembro de 2011. A coleta de dados foi feita a partir de instrumentos qualitativos e quantitativos. Foram aplicadas entrevistas estruturadas nas comunidades de Lages, Paituna e Santana. O software SPHINX foi utilizado para compilação e análise dos dados. Foram feitas também entrevistas abertas e semiestruturadas com funcionários da SEMA/PA. As entrevistas foram gravadas e, posteriormente, transcritas para análise.

Este trabalho verificou que a criação do PEMA, ao restringir o uso dos recursos naturais, atingiu desfavoravelmente as atividades desenvolvidas pelas comunidades ribeirinhas residentes na região. Assim, a principal conclusão do artigo é que política de conservação da biodiversidade impõe impactos negativos aos moradores localizados nas proximidades da UC ou em seu interior.

\section{UNIDADES DE CONSERVAÇÃO NO BRASIL}

A ideia de reservas com vastas superfícies nasceu nos Estados Unidos, em 1872, quando foi criado Yellowstone, o primeiro parque nacional do país. No Brasil, a primeira proposta de criação de parques nacionais foi bastante precoce. Em 1876, inspirado no exemplo norte-americano, o engenheiro André Rebouças sugeriu a criação de dois parques nacionais no país: um na Ilha do Bananal (rio Araguaia) e outro em Sete Quedas (rio Paraná) (DRUMMOND; FRANCO; NINIS, 2005; PÁDUA, 1997).

Apesar da antiguidade das propostas de Rebouças, o primeiro parque brasileiro só foi criado em 1937, na divisa de Minas Gerais e Rio de Janeiro, o Parque Nacional de Itatiaia. Em 1939, foram criados dois outros parques no país: o Parque Nacional do Iguaçu, no Paraná, e o Parque Nacional da Serra dos Órgãos, no Rio de Janeiro (BENSUSAN, 2006). 
Inicialmente, os parques nacionais foram criados, sobretudo, no Sul e Sudeste, regiões mais populosas e urbanizadas do país. Somente a partir da década de 1970, com a expansão da fronteira agrícola e a destruição de florestas tropicais, o governo brasileiro criou os primeiros parques na Amazônia. Em 1974, foi criado o Parque Nacional da Amazônia, em Itaituba (Pará) e, em 1979, dois novos parques foram criados na região amazônica: Pico da Neblina (Amazonas) e Pacaás Novos (Rondônia) (DIEGUES, 1994). Desde então, o número de UCs e a extensão das áreas protegidas para fins ambientais vêm crescendo aceleradamente tanto no nível federal como nos níveis estadual e municipal.

O aumento do número de unidade de conservação - atualmente 8,5\% da superfície do Brasil está coberta por UCs federais ${ }^{2}$ - exigiu a sistematização e o gerenciamento de áreas protegidas no país. Dessa forma, a Lei do SNUC (Sistema Nacional de Unidades de Conservação), Lei no 9.985, de 18 de julho de 2000, estabeleceu critérios e normas de criação, implantação e gestão das UCs. A lei definiu unidade de conservação como:

Espaço territorial e seus recursos ambientais, incluindo as águas jurisdicionais, com características naturais relevantes, legalmente instituído pelo Poder Público, com objetivos de conservação e limites definidos, sob regime especial de administração, ao qual se aplicam garantias adequadas de proteção (Lei No 9.985, de julho de 2000).

A principal inovação da Lei do SNUC foi a divisão das UCs em dois grupos: as áreas de proteção integral, com o objetivo básico de preservar a natureza, admitindo-se apenas o uso indireto dos recursos naturais; e as áreas de uso sustentável, cuja finalidade é compatibilizar a conservação da natureza com o uso sustentável de parcela dos seus recursos naturais. Ao primeiro grupo pertencem cinco categorias: Estação Ecológica, Reserva Biológica, Parque Nacional - quando criado pelo estado ou município é denominado Parque Estadual ou Parque Natural Municipal -, Monumento Natural e Refúgio de Vida Silvestre. Sete categorias fazem parte do segundo grupo: Área de Proteção Ambiental, Área de Relevante Interesse Ecológico, Floresta Nacional - quando criada pelo estado ou município é denominada Floresta Estadual ou Floresta Municipal -, Reserva Extrativista, Reserva de Desenvolvimento Sustentável, Reserva de Fauna e Reserva Particular do Patrimônio Natural (DRUMMOND; FRANCO; NINIS, 2005).

O foco deste estudo são os Parques, estabelecidos para:

2 Fonte: <www.icmbio.gov.br>. Acesso em: 16 nov. 2011. 
A preservação de ecossistemas naturais de grande relevância ecológica e beleza cênica, possibilitando a realização de pesquisas científicas e o desenvolvimento de atividades de educação e interpretação ambiental, de recreação em contato com a natureza e de turismo ecológico. (Lei n $\left.{ }^{\circ} 9.985 / 2000\right)$.

Por se tratar de uma área de proteção integral, o Parque não admite a moradia de pessoas em seu interior, mesmo as que habitam a região há dezenas e até centenas de $\operatorname{anos}^{3}$. Este impedimento gera conflitos entre os "antigos" residentes da área e as instituições gestoras da UC. Essas disputas estão relacionadas às restrições ao uso dos recursos naturais impostas às populações locais. Estas, após a criação da UC de proteção integral, ficam impedidas de realizar práticas habituais, tais como a pesca, a caça, a extração mineral, a agricultura e a pecuária.

Na próxima seção, será analisado o conceito de conflito social, com base em Simmel e na teoria de social de Bourdieu. A partir desse marco teórico, busca-se compreender como os moradores de áreas protegidas se acomodam ou resistem às mudanças provocadas pela criação de UCs.

\section{CONFLITOS SOCIAIS}

No debate científico e político na área social há uma ampla gama de abordagens que trata de conflitos. Sem pretender esgotar as discussões conceituais, nem abdicar do rigor científico, é apresentada aqui uma breve incursão nos debates em torno de conflitos sociais.

Diversos campos do conhecimento, da Psicologia à Economia, contribuíram para a interpretação de conflitos. No entanto, entre as várias disciplinas, parte do debate ficou até recentemente reduzido ao campo da Sociologia, que desde os seus primórdios se dedica ao estudo dos conflitos para a compreensão da sociedade moderna (NASCIMENTO, 2001).

De acordo com Vayrynen (1991), é possível diferenciar duas grandes correntes teóricas sobre o conflito na literatura das Ciências Sociais: conflict resolution e conflict transformation. Para a primeira abordagem, os conflitos são distúrbios na ordem dos sistemas sociais. Eles são considerados uma contingência negativa em

\footnotetext{
A Lei do SNUC (Art.42) só admite como solução para a presença de populações tradicionais em Unidade de Proteção Integral a sua remoção e reassentamento, a não ser em caso de superposição com áreas indígenas. O Art. 57 da referida Lei afirma que: "os órgãos federais responsáveis pela execução das políticas ambiental e indigenista deverão instituir grupos de trabalho para [...] propor as diretrizes a serem adotadas com vistas à regularização das eventuais superposições entre áreas indígenas e unidades de conservação" (Lei do SNUC).
} 
um sistema equilibrado e, por isso, devem ser neutralizados ou mitigados. Para os defensores de conflict resolution (ou resolução de conflito), os conflitos são vistos como provisórios, devendo ser resolvidos de forma permanente por mecanismos de intervenção, tais como a mediação e a negociação (AN-NA'IM; PESHKOVA, 2000; SEGATO, 2006).

Vários autores, como Pareto (1984), Merton (1970) e, sobretudo, no âmbito do funcionalismo, com o Parsons (1979), fazem parte da corrente teórica conflict resolution. Para eles, os conflitos são entendidos como anomia, ou seja, resultam da ausência de normas (DURKHEIM, 2000). Os conflitos são sinais de disfunção, de perturbação e de desequilíbrio da sociedade, devendo, portanto, ser resolvidos. A negatividade do conceito é explícita. Segundo esses autores, os conflitos decorrem do mau funcionamento do sistema e criam problemas para a sociedade moderna (NASCIMENTO, 2001).

A segunda abordagem entende que os conflitos são inerentes a qualquer sistema social, funcionando como propulsores de mudanças. Aqui o conflito assume uma positividade ímpar. Para os defensores de conflict transformation (ou transformação do conflito), o conflito é fenômeno natural que transforma eventos, relações entre os atores envolvidos e seus criadores (LEDERACH, 1995). Esta abordagem reconhece que, sem confrontos, as transformações e os crescimentos pessoais, comunitários e sociais não seriam possíveis. O conflito deve ser visto, portanto, como um agente transformador (AN-NA'IM; PESHKOVA, 2000).

Em contraposição à negatividade pura, descrita pelos autores da corrente conflict resolution, o conflito contém algo de positivo para Marx e Simmel, autores pertencentes à abordagem conflict transformation.

Para Marx, o conflito deriva da luta de classes, considerada o motor da história da humanidade. Em outras palavras, é ele o responsável pelas transformações sociais e pelo progresso. Como os interesses das classes sociais são inconciliáveis, a única hipótese de solução dos conflitos desta natureza é a destruição de um dos termos da tensão (NASCIMENTO, 2001).

De acordo com Marx, a noção de conflito aparece como tensão no interior das estruturas sociais ou em seus próprios termos, como antagonismo entre a infra e a superestrutura. A primeira é constituída essencialmente pelas forças e relações de produção; na superestrutura figuram as instituições jurídicas e políticas, bem como o modo de pensar, as ideologias e as filosofias (ARON, 2003). Marx considera que as sociedades modernas são eivadas de contradições, de tipos muito distintos, mas todas submetidas à contradição maior, a saber, a contradição entre capital e trabalho. 
Porém, a concepção do conflito em Marx, apesar de ser rica, tende ao reducionismo, pois o autor submete todas as tensões sociais a um conflito central. Os conflitos transformam-se, assim, em epifenômenos sociais, sem realidade própria. O corpo teórico de Marx perde grande parte de sua riqueza, deixando escapar as nuances e particularidades da profusão de conflitos que conformam nossa sociedade (NASCIMENTO, 2001, p. 93).

É em Simmel que a noção de conflito reveste-se da maior positividade. E por isso, este trabalho se atém mais detalhadamente às contribuições deste autor. Para Simmel (1983), os conflitos são inerentes à própria formação da sociedade. Eles são partes integrantes das relações humanas, sendo responsáveis pelas mudanças nos grupos de interesse, uniões e organizações.

Para Simmel (1983), o conflito está destinado a resolver dualismos divergentes - uma maneira de restituir a unidade perdida, ainda que por meio da aniquilação de uma das partes conflitantes. Assim, o confronto não constitui sinal de falta de integração das sociedades, mas sim elemento vital para a renovação e unidade das mesmas. O conflito é uma das formas mais vivas de interação, constituindo uma forma de sociação (SIMMEL, 1983):

Se toda interação entre os homens é uma sociação, o conflito - afinal, uma das mais vívidas interações e que, além disso, não pode ser exercida por um indivíduo apenas - deve certamente ser considerado uma sociação. (SIMMEL, 1983, p. 122).

Segundo o autor, a sociedade, para alcançar determinada configuração, necessita de quantidades proporcionais de harmonia e desarmonia, de associação e competição, de tendências favoráveis e desfavoráveis. Ambas as relações antitética e convergente - são encontradas em situações historicamente reais. Essas discordâncias não são meras deficiências sociológicas ou exemplos negativos, como preveem Parsons (1979) e Merton (1970). Para Simmel (1983), a sociedade resulta de ambas as categorias de interação, que são inteiramente positivas. $O$ desaparecimento de energias de repulsão não resulta numa vida social mais rica e mais plena, mas num fenômeno irrealizável, da mesma maneira se o grupo fosse privado das forças de cooperação, afeição, ajuda mútua e convergência de interesses.

Portanto, os conflitos são, para Simmel (1983), partes integrantes da trama social e fundamentais para a integração do grupo. Entretanto, o autor afirma que as relações de conflito, por si mesmas, não podem produzir uma estrutura social. A sociação ocorre somente em cooperação com forças unificadoras. Segundo Simmel (1983, p. 128), "a essência da alma humana não permite que um indivíduo se ligue a outro por um elo apenas". Somente a junção dos elos associativos e dissociativos constitui a relação social como uma unidade viva e concreta. 


\section{O CAMPO DOS CONFLITOS AMBIENTAIS}

Nas sociedades contemporâneas, uma modalidade particular de conflito adquiriu importância: os conflitos em torno do meio ambiente ou dos recursos naturais. Os conflitos socioambientais são "disputas entre grupos sociais derivadas dos distintos tipos de relação que eles mantêm com seu meio natural" (LITTLE, 2001, p. 107).

Os conflitos ambientais são emblemáticos das contradições entre distintos projetos de apropriação e significação do mundo material. E, ao contrário da visão funcionalista, para a qual os conflitos são um simples sinal de que algo não vai bem, há que se considerar que na disputa entre atores há uma positividade. Este trabalho assume, portanto, a noção de conflito desenvolvida por Georg Simmel. Ou seja, considera-se o conflito como meio para atenuar as divergências, sendo fator de coesão social e não de distúrbio.

Para compreender e interpretar os conflitos ambientais verificados na modernidade, além de Simmel, este estudo se remete à teoria social de Bourdieu. O meio ambiente é aqui analisado como um campo específico de construção e manifestação de conflitos. De acordo com Bourdieu (1983), o campo é um espaço estruturado, onde se constituem relações de concorrência e de disputa de poder entre agentes nele situados.

Em Bourdieu, o significado de campo é apreendido a partir de uma perspectiva relacional do mundo social. Para Bourdieu (1996, p. 16), "o real é relacional". Assim, indivíduos ou grupos ocupam posições relativas num espaço social e travam embates, cada qual com possibilidades diferenciadas de obter êxito. As posições são consideradas relativas por serem definidas umas com relação às outras, de acordo com os respectivos volumes de poder que possuem.

O campo ambiental, tal como os campos político e jurídico descritos por Bourdieu, constitui-se em um espaço social de diferenciações, onde são travadas lutas entre os agentes nele encontrados (BOURDIEU, 1996). Neste espaço, os agentes se esforçam para conservar ou transformar a estrutura das relações existentes. Especificamente, no interior do campo ambiental, os agentes estão dispostos de acordo com estruturas desiguais de acesso, uso, apropriação, distribuição e controle sobre os territórios e sobre o conjunto de recursos materiais e simbólicos.

É possível discriminar dois espaços onde se definem as relações de poder nas sociedades (ACSELRAD, 2004). Para efeitos da questão ambiental, o primeiro deles é o espaço da distribuição do poder sobre o "capital material". Neste espaço, configura-se a capacidade diferencial dos agentes de terem acesso à 
terra fértil, a fontes de água, aos recursos naturais vivos etc. O segundo é o espaço onde se confrontam as representações, valores e percepções que organizam as diferentes visões a respeito do mundo natural. Trata-se do espaço onde ocorrem disputas pelo "capital simbólico" da natureza.

Neste artigo, as disputas pelos recursos naturais ("capital material") contidos no interior de uma unidade de conservação de proteção integral são analisadas a partir do estudo do Parque Estadual Monte Alegre (PEMA-PA). A criação do PEMA, ao restringir o uso dos recursos naturais, prejudicou a agricultura familiar e a pesca artesanal, desencadeando conflitos entre os gestores da UC (SEMA-PA) e os residentes locais. Assim, nota-se que as normas restritivas ao uso de recursos naturais como opção por um tipo de política de conservação da biodiversidade, impõem impactos negativos aos moradores do interior e do entorno da UC.

Considera-se que o entendimento e a eventual resolução dos conflitos entre os ribeirinhos e os demais agentes governamentais envolvidos com o Parque podem alterar o atual cenário de suspensão de direitos dos moradores locais e, assim, eliminar os impedimentos legais de plantar roças, de reformar residências (muitas vezes bem deterioradas), de extrair recursos florestais essenciais a sua sobrevivência, dentre tantas outras restrições impostas pela criação do PEMA.

\section{ESTUDO DE CASO: O PARQUE ESTADUAL MONTE ALEGRE}

O Parque Estadual Monte Alegre (PEMA), criado pela lei estadual $\mathrm{n}^{\mathrm{o}}$ 6.412, de 9 de novembro de 2001, encontra-se ao sul de Monte Alegre. Este município está localizado na porção noroeste do estado do Pará e se situa na margem esquerda do rio Amazonas. Pertence à Mesorregião do Baixo Amazonas, Microrregião de Santarém (BRASIL, 2009). Monte Alegre ocupa uma área de 18.152,508 $\mathrm{km}^{2}$ e faz fronteira com os municípios de Almeirim, Alenquer, Santarém e Prainha ${ }^{4}$. A cidade de Monte Alegre, sede municipal, situa-se na porção sul-sudeste do município (Figura 1).

Mais de $50 \%$ da área do município de Monte Alegre é coberta por áreas protegidas. O PEMA, com área de $58 \mathrm{~km}^{2}$ e perímetro de $46.377 \mathrm{~m}$, está inserido em sua totalidade na Área de Proteção Ambiental (APA) Paytuna (BRASIL, 2009) (Figura 2). Além dessas duas unidades de conservação estaduais, o município apresenta outras quatro UCs, das quais três são estaduais (Estação Ecológica do Grão-Pará, Reserva Biológica Maicuru e Floresta Estadual do Paru) e uma

4 Fonte: <http://www.ibge.gov.br/cidadesat>. Acesso em: 11 dez. 2011. 
é federal (Floresta Nacional de Mulata). Além disso, Monte Alegre possui uma Terra Indígena, chamada de Rio Paru d'Eeste (BRASIL, 2009).

Figura 1: Localização do município de Monte Alegre.
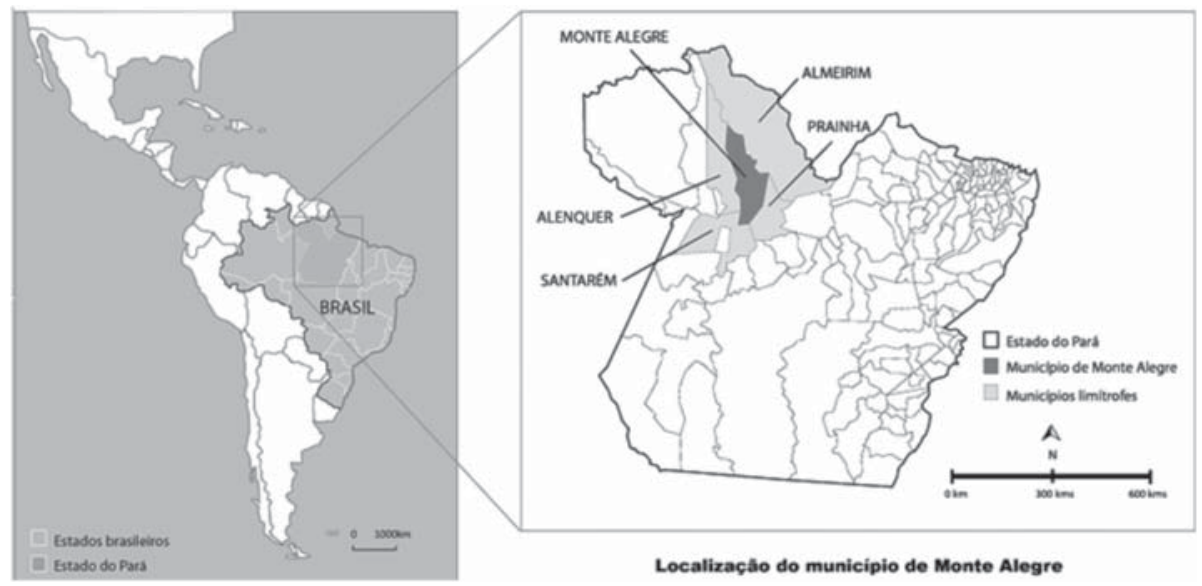

Fonte: S. Nasuti (2012).

O PEMA foi criado com o objetivo principal de proteger os sítios arqueológicos da região. Monte Alegre é o terceiro município do estado Pará em número de sítios arqueológicos com arte rupestre. Até o momento, estão cadastrados 26 sítios arqueológicos em Monte Alegre. Deste total, 15 estão dentro dos limites do PEMA. Todos os sítios localizados no interior PEMA apresentam pinturas rupestres (BRASIL, 2009).

Apesar de as pinturas rupestres serem o vestígio arqueológico mais conhecido de Monte Alegre, outros tipos de materiais arqueológicos como cerâmicas e artefatos em pedra também ocorrem na região, mas poucas pessoas têm conhecimento e nunca foram datados. As cerâmicas encontradas no município foram caracterizadas como Cultura Santarém, presente em toda a região do Baixo Amazonas.

As características estilísticas das pinturas rupestres de Monte Alegre não encontram paralelo no restante do Brasil. A arte rupestre encontrada no município é a única que utiliza determinadas formas da rocha, tais como orifícios, arestas ou protuberâncias para compor as figuras ou dar volume a elas. Nas pinturas rupestres da região foram identificados cinco temas: antropomorfos, mãos, zoomorfos, biomorfos e grafismos puros (BRASIL, 2009).

O conhecimento acumulado em quase dois séculos sobre os aspectos arqueológicos e geológicos de Monte Alegre, somado às belezas cênicas da região, atraíram a atenção do governo para a criação de áreas protegidas no Novos Cadernos NAEA •v. 15 n. $2 \cdot$ p. 21-44 • dez. 2012 
município (BRASIL, 2009). No entanto, é importante ir além de interpretações que condicionam a criação de UCs apenas a fatores naturais, geológicos e arqueológicos, "como se estes gozassem de uma existência exterior e independente dos processos socioculturais" (BARRETTO, 1997, p. 10).

A criação do PEMA vincula-se ao Programa de Desenvolvimento do Ecoturismo na Amazônia Legal (Proecotur). Coordenado pelo Ministério do Meio Ambiente (MMA), por intermédio da Secretaria de Coordenação da Amazônia (SCA), o Proecotur tinha o objetivo principal de "viabilizar o ecoturismo como uma atividade sustentável para o desenvolvimento da Amazônia Legal" (PNUD, 1999, p. 18). Entre os objetivos específicos estavam o apoio e o desenvolvimento de estudos para criação, planejamento e gestão de unidades de conservação na Amazônia. Financiado pelo Governo Federal brasileiro e pelo Banco Interamericano de Desenvolvimento (BID), o Proecotur contou com um montante de US\$11 milhões na fase de pré-investimentos - e de US\$200 milhões na fase de investimentos (PNUD, 1999).

Figura 2: Áreas protegidas existentes no município de Monte Alegre (PA).

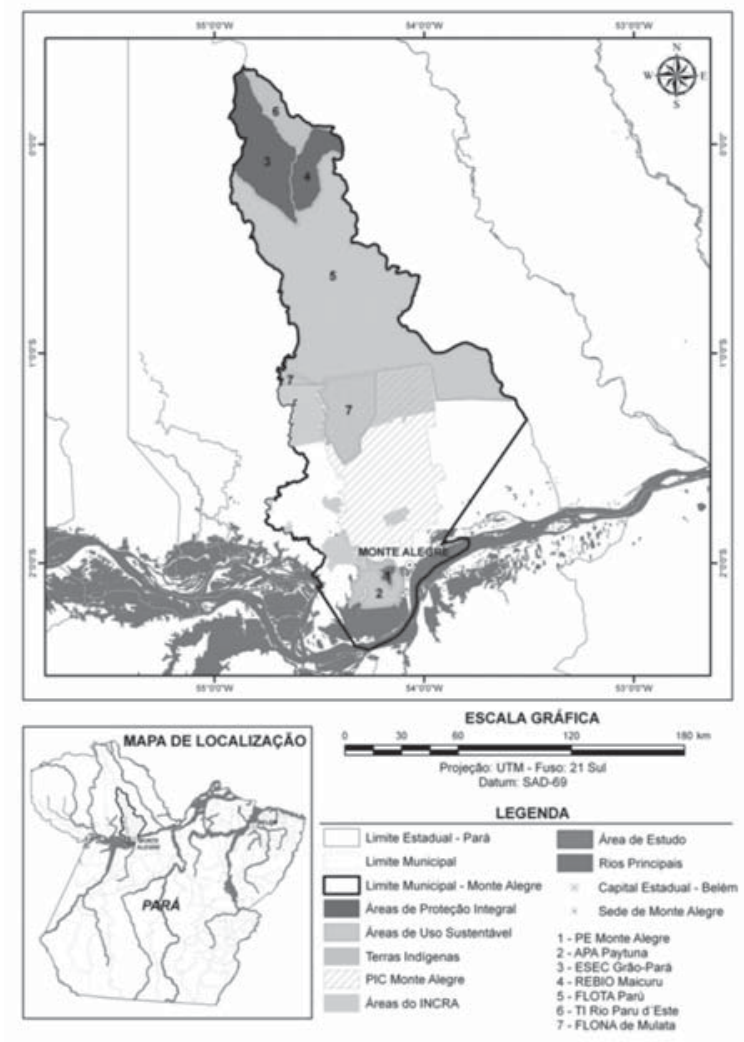

Fonte: BRASIL (2009). 
A fim de captar parte desses recursos e participar do Proecotur, o governo estadual do Pará elaborou o Plano de Desenvolvimento Turístico do Estado do Pará. O Plano propõe a criação de unidades de conservação em Monte Alegre, munícipio pertencente ao Polo Tapajós. Em 2000, com a instalação do Proecotur ${ }^{5}$ na Secretaria de Estado de Ciência, Tecnologia e Meio Ambiente do Pará $\left(\operatorname{Sectam}^{6}\right)$, iniciaram-se as ações estabelecidas no Plano de Desenvolvimento Turístico do Estado. Entre as ações estava a realização de estudos técnicos em Monte Alegre para a criação de UCs. Para isso, a Sectam contratou, em 2001, o Museu Paraense Emílio Goeldi.

Após a conclusão dos estudos técnicos, o Proecotur patrocinou o $I$ Seminário para Criação de Unidades de Conservação no Município de Monte Alegre. Este seminário visou garantir o envolvimento da sociedade local na discussão. Tratavase da consulta pública obrigatória, conforme previsto na Lei do SNUC, capítulo IV, artigo 22, \ $2^{\circ}$ : “a criação de uma unidade de conservação deve ser precedida de estudos técnicos e de consulta pública que permitam identificar a localização, a dimensão e os limites mais adequados para a unidade”.

O objetivo do Seminário, realizado no dia 18 de junho de 2001, na sede do município de Monte Alegre, foi apresentar à população local as propostas referentes à criação de UCs no município. E caso elas fossem aprovadas, discutir as delimitações, as nomeações e as categorias de manejo (BRASIL, 2009). Ao final do Seminário, chegou-se à decisão de se criar um Parque restrito à área onde não houvesse moradores $\left(36,78 \mathrm{~km}^{2}\right.$ ), e uma Área de Proteção Ambiental (APA), que abrangeria o restante da área e funcionaria como zona de amortecimento do Parque.

Contudo, a proposta aprovada na consulta pública não foi respeitada. Durante a elaboração dos Anteprojetos de Lei que criaram o PEMA e a APA Paytuna (Lei estadual n ${ }^{\circ} 6412$ e Lei estadual n 6426), a comunidade de Lages foi inserida no interior do Parque (Figura 2). Além das famílias de Lages, residentes de outras comunidades foram prejudicados por essa lei. Muitos moradores de Paituna e Santana também possuem terras no interior do Parque. Essas terras são utilizadas para lavoura, criação de gado, retirada de madeira para a construção de casas etc. (BRASIL, 2009).

Uma área correspondente a 63\% do Parque sobrepõe terras de ribeirinhos locais (BRASIL, 2009). Considerando as três comunidades de estudo, observa-se que a comunidade de Lages encontra-se na situação mais delicada, uma vez que

5 Em 2002, o Proecotur foi retirado da Sectam e transferido para a Paratur (Empresa Paraense de Turismo) (SILVA, 2008).

6 Em 2007, a Sectam foi desmembrada em duas Secretarias: a Secretaria de Estado de Desenvolvimento, Ciência e Tecnologia (Sedect) e a Secretaria de Estado de Meio Ambiente (SEMA). 
ela está totalmente inserida no Parque. No entanto, os moradores das demais comunidades também perderam parte da propriedade, a saber, os fundos de seus estabelecimentos rurais ${ }^{7}$. A maioria dos moradores não possui escrituras de terras e/ou registros no cartório de imóveis. Até o final de 2011, nenhum deles foi indenizado pela perda parcial ou total da propriedade. Da mesma forma, ninguém foi expulso do local.

\section{COMUNIDADES RIBEIRINHAS: LAGES, PAITUNA E SANTANA}

Nesta seção são apresentadas informações sobre as comunidades ribeirinhas do interior e do entorno do PEMA. Esses dados foram coletados durante trabalho de campo realizado em agosto e setembro de 2011. Na Amazônia, o difícil acesso às famílias dificulta a realização da pesquisa de campo. Dessa forma, as famílias entrevistadas foram selecionadas principalmente pelo critério de acessibilidade. Buscou-se também visitar o máximo de estabelecimentos possíveis, evitando fatores de aglomeração que poderiam comprometer o estudo, como concentração geográfica (Figura 3).

Figura 3: Localização das famílias de Lages, Paituna e Santana entrevistadas em 2011.

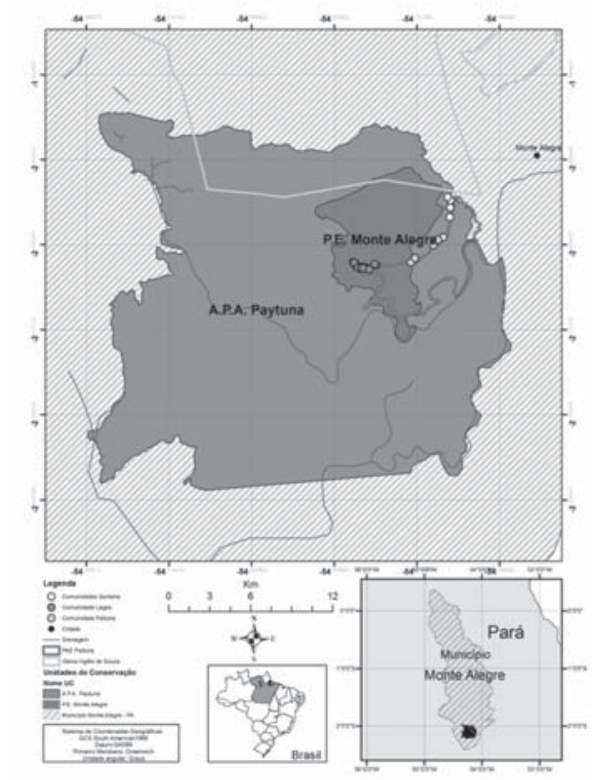

Fonte: Torres (2012).

Quatro famílias de Paituna encontram-se inteiramente no interior do PEMA. Informação coletada, em agosto de 2011, com técnicos do escritório local da Emater, em Monte Alegre (PA). 
No âmbito da pesquisa, foram entrevistados 37 moradores de Lages, Paituna e Santana ${ }^{8}$. Deste total, 27 entrevistas foram realizadas na comunidade Lages. A pesquisa se concentrou nesta comunidade, por ela estar totalmente inserida no interior do Parque Estadual Monte Alegre e ser, portanto, a mais diretamente afetada pela restrição ao uso dos recursos naturais. Realizaramse também 5 entrevistas em Paituna e 5 em Santana (Figura 1). O objetivo foi comparar os resultados das três comunidades e observar possíveis especificidades de Lages (Tabela 1).

Tabela 1: Percentual de famílias entrevistadas.

\begin{tabular}{c|c|c|c}
\hline Comunidade & População & Número de famílias & Famílias entrevistadas \\
\hline PAE Paituna & 486 & 129 & $\begin{array}{c}37 \\
(28,6 \%)\end{array}$ \\
\hline LAGES & 151 & 35 & $\begin{array}{c}27 \\
(77 \%)\end{array}$ \\
\hline PAITUNA & 170 & 55 & 5 \\
\hline SANTANA & 165 & 39 & 5 \\
\hline
\end{tabular}

Fonte: Secretaria de Saúde de Monte Alegre (SIAB/SESMA) - Agente de Saúde do PAE Paituna (Rosilda de Almeida Andrade).

Dentre as três comunidades estudadas, Paituna é a mais antiga. Registros históricos apontam a presença de residentes nessa comunidade já em 1832 (SILVA, 2008). A divisão dos limites físicos das comunidades de Paituna e Santana é tênue até mesmo para os moradores locais. Os mais jovens classificam a comunidade de Santana como um "bairro" de Paituna (SILVA, 2008). Não foram encontradas muitas informações a respeito da origem da comunidade de Santana. Porém, estima-se que ela exista desde o século XIX (SILVA, 2008). Lages é a mais nova das três comunidades visitadas. A formação de Lages ocorreu por volta de 1950, quando os moradores do local se uniram e deram nome à comunidade ${ }^{9}$

Todos os entrevistados nasceram em Monte Alegre e a maioria deles (62\%) é natural da própria comunidade em que reside atualmente. Cerca de 70\% dos entrevistados moram na propriedade há mais de 20 anos (Tabela 2). Nota-se, portanto, que a maioria deles está no local antes da criação do Parque Estadual de Monte Alegre em 2001.

\footnotetext{
8 Buscou-se realizar entrevistas com o chefe de família. Nas casas em que ele não se encontrava, foram realizadas entrevistas com as pessoas que respondiam pelo estabelecimento na ausência do chefe.

9 Informação coletada em um folheto de igreja, em agosto de 2011.
}

Novos Cadernos NAEA • v. 15 n. $2 \cdot$ p. 21-44 • dez. 2012 
Tabela 2: Tempo de residência na propriedade - entrevistados.

\begin{tabular}{l|c|c}
\hline Tempo de residência & Frequência & $\mathbf{\%}$ \\
\hline Menos de 10 anos & 4 & 10,81 \\
\hline De 10 a 20 anos & 3 & 8,11 \\
\hline De 20 a 30 anos & 11 & 29,73 \\
\hline De 30 a mais & 15 & 40,54 \\
\hline NS/NR & 4 & 10,81 \\
\hline Total & $\mathbf{3 7}$ & $\mathbf{1 0 0}$ \\
\hline
\end{tabular}

Fonte: Pesquisa de Campo (2011).

Nas comunidades ribeirinhas de Lages, Paituna e Santana, a economia está assentada sobre atividades agrícolas, pecuárias e, notadamente, sobre a pesca: $70,2 \%$ dos entrevistados afirmaram que a atividade pesqueira é a principal fonte de renda da família. A pesca é uma atividade relevante tanto para a subsistência como para o comércio. Os peixes constituem o componente mais importante da alimentação das famílias da região.

Nas comunidades estudadas, a agricultura está direcionada principalmente para a subsistência, exceto o feijão, que é vendido por algumas poucas famílias na cidade de Monte Alegre. A mandioca é um dos produtos mais plantados: 46\% dos entrevistados a cultivam. A mandioca, principal fonte de carboidrato dos ribeirinhos, é utilizada para fazer farinha, tucupi, tapioca e goma (Tabela 3).

Tabela 3: Variedades de plantios (tipos de cultivos - entrevistados).

\begin{tabular}{l|c|c|c|c|c}
\hline & $\begin{array}{c}\text { Plantio de } \\
\text { milho/arroz }\end{array}$ & $\begin{array}{c}\text { Plantio de } \\
\text { feijão }\end{array}$ & $\begin{array}{c}\text { Plantio de } \\
\text { mandioca }\end{array}$ & $\begin{array}{c}\text { Plantio de } \\
\text { hortaliças }\end{array}$ & $\begin{array}{c}\text { Plantio de } \\
\text { frutíferas }\end{array}$ \\
\hline Sim & 10 & 4 & 17 & 20 & 34 \\
\hline Não & 27 & 32 & 20 & 15 & 3 \\
\hline NS/NR & 0 & 1 & 0 & 2 & 0 \\
\hline Total & 37 & 37 & 37 & 37 & 37 \\
\hline
\end{tabular}

Fonte: Pesquisa de Campo (2011).

Os moradores destinam seus terrenos para a agricultura, para a pecuária ou combinam as duas atividades no mesmo espaço. As áreas cultivadas devem ser cercadas para evitar destruições causadas pelo gado que circula livremente entre os estabelecimentos rurais. Mesmo moradores que apenas plantam e não 
criam - ou mantêm criações em outros terrenos, podem ter problemas com gado invadindo seus roçados. Esta é uma fonte constante de conflitos entre vizinhos.

O manejo do gado e das pastagens obedece ao ciclo das águas: o transporte de gado entre áreas de terra firme e de várzea é comum entre os ribeirinhos. $\mathrm{Na}$ estação seca, os terrenos de várzea que permaneceram submersos no período chuvoso, enchem-se de capim. Assim, aproveitando-se da fertilidade dos campos naturais, os criadores de gado deslocam suas reses para a várzea. Já na estação chuvosa, os moradores costumam levar seus rebanhos para áreas de terra firme.

A presença do gado branco (de corte) nas comunidades é significativa: 54\% dos entrevistados criam bovinos. Porém, trata-se de pequena criação de gado: 6,2 cabeças por família. Em geral, o gado representa uma forma de poupança para os moradores das comunidades visitadas. O rebanho é fruto de investimentos feitos a partir dos rendimentos obtidos com a pesca ou a agricultura. Boa parte das famílias visitadas também cria galinhas, porcos e patos, como demonstra a Tabela 4. Essas criações são utilizadas principalmente para alimentação das famílias. No entanto, pequena parte é vendida.

Tabela 4: Criação de animais - entrevistados.

\begin{tabular}{c|c|c|c|c|}
\hline & $\begin{array}{c}\text { Criação de } \\
\text { bovinos }\end{array}$ & $\begin{array}{c}\text { Criação de } \\
\text { galinhas }\end{array}$ & $\begin{array}{c}\text { Criação de } \\
\text { porcos }\end{array}$ & $\begin{array}{c}\text { Criação de } \\
\text { patos }\end{array}$ \\
\hline Sim & 20 & 35 & 16 & 12 \\
\hline Não & 17 & 2 & 21 & 25 \\
\hline Total & 37 & 37 & 37 & 37 \\
\hline
\end{tabular}

Fonte: Pesquisa de Campo (2011).

Por fim, deve-se destacar que $97,3 \%$ dos entrevistados possuem fontes de renda externas à propriedade, tais como aposentadorias e pensões, bolsa família, seguro defeso, prestação de serviço no campo, prestação de serviço na cidade e prestação de serviço para o estado ou município. Este dado realça a importância dos programas de transferências de renda, como o Programa Bolsa Família, para a composição da renda familiar dos ribeirinhos de Lages, Paituna e Santana.

Neste sentido, convém ressaltar que o Governo Federal repassou, em 2010, R \$ 9.844.863,00 diretamente às famílias em condição de pobreza e extrema pobreza residentes em Monte Alegre (Programa Bolsa Família, Lei n ${ }^{\circ}$ 10.836, de 2004). No total, o município possui 9.539 beneficiários do Programa Bolsa Família, ou seja, 17,2\% da população ${ }^{10}$. Assim, o Programa Bolsa Família é

10 Fonte: <http://pa.transparencia.gov.br/Monte_Alegre>. Acesso em: 2 jan. 2012. 
importante não apenas para as comunidades estudadas, como também para parte significativa dos habitantes do município.

\section{CONFLITOS PELA CONSERVAÇÃO/USO DOS RECURSOS NATURAIS DO PEMA}

Com base em Bourdieu (1996), foram definidos para este estudo dois espaços sociais (campos) de disputas: o primeiro se define por embates pela apropriação dos recursos naturais (capital material); e o segundo é caracterizado por disputas entre as distintas formas sociais de significação da natureza (capital simbólico).

A presença de populações humanas tanto no interior quanto no entorno de áreas protegidas de uso indireto gera conflitos com a administração das unidades de conservação, pela utilização dos recursos naturais mediante a pesca, a caça, a extração de produtos vegetais, a agricultura e a pecuária. Nesta seção são analisados os conflitos entre a SEMA e as comunidades ribeirinhas, advindos do processo de institucionalização de restrições legais ao uso dos recursos naturais na área investigada. Vale salientar que os conflitos envolvem relações de poder desiguais (ex.: SEMA x populações ribeirinhas). Trata-se, portanto, de conflitos assimétricos, que ocorrem entre atores situados em posições distintas de poder.

Para a comunidade de Lages, a proporção maior de conflitos tem origem na pesca e no uso da terra para plantação e criação. Entre os entrevistados, 77,8\% afirmaram pescar (para subsistência) no Lago das Dores. Este se situa no interior da área de proteção integral. Portanto, não poderia ser utilizado para este fim. Há também conflitos gerados pela extração de produtos florestais e pela caça. Do total de entrevistados, em Lages, 55,6\% declararam coletar recursos na mata e $74,1 \%$ afirmaram comer carne de caça.

Já para as comunidades de Paituna e Santana, boa parte dos conflitos se origina no uso da terra. Como não sabem os limites exatos do PEMA, os entrevistados declararam temer multas da SEMA e/ou do IBAMA, em função de suas plantações e criações em parte dos estabelecimentos rurais. Ademais, foram observados conflitos decorrentes da extração de produtos florestais e da caça. Dos entrevistados em Paituna e Santana 70\% declararam coletar recursos na mata e 40\% afirmaram comer carne de caça. Não foram observados conflitos gerados pela exploração de recursos pesqueiros, pois os moradores dessas duas comunidades pescam em lagos e rios localizados na APA Paytuna e não no PEMA. 
As restrições ao uso dos recursos naturais do PEMA provocaram mudanças no modo de vida das populações ribeirinhas. A principal mudança ocorreu na produção agrícola: 78,4\% dos entrevistados declararam que após a criação do Parque passaram a plantar menos gêneros alimentícios. A comunidade mais prejudicada foi Lages. Com a criação do Parque, muitas famílias deixaram de plantar feijão e mandioca no local. Anteriormente, o feijão era vendido na cidade e a renda gerada complementava o orçamento familiar. Além disso, a impossibilidade de plantar mandioca na área obrigou alguns chefes de família a comprar farinha (ou mandioca) e a trabalhar como meeiros em outras terras. Quando perguntados sobre o motivo pelo qual diminuíram o plantio, a maioria dos entrevistados se referiu às proibições impostas pelo Parque. No entanto, duas pessoas responderam que a diminuição da atividade agrícola se deu em função de invasões de porcos de propriedades vizinhas. Os porcos, por serem criados soltos, destroem as plantações.

Foram observadas também mudanças na atividade criatória: 35,1\% dos entrevistados declararam que após a criação do PEMA passaram a ter uma criação de animais menor (bois, porcos, galinhas e patos). A maioria dos entrevistados afirmou que a diminuição da criação de animais ocorreu em decorrência das proibições advindas com a criação do Parque. No entanto, três pessoas responderam que a diminuição da atividade criatória se deu em função: (1) de ter saído da região; (2) de ter ficado mais velho; (3) de ter ficado doente.

Quando perguntados sobre a influência do Parque sobre a pesca, apenas $20 \%$ dos entrevistados disseram que após a criação do PEMA passaram a pescar menos. De acordo com eles, a diminuição da atividade pesqueira está relacionada às proibições impostas pelo Parque, à exceção de um entrevistado, segundo o qual a diminuição da pesca deve-se à redução do número de peixes na região. Por fim, foram detectadas mudanças nos hábitos alimentares: 43,2\% dos entrevistados declararam que diminuíram o consumo de carne de caça em função do PEMA.

Apesar de saberem das restrições impostas pelo Parque, 70,3\% dos entrevistados não concordam com elas. Para 73\%, o PEMA trouxe malefícios para as populações locais. Os principais problemas citados foram: (1) proibições de plantar; e (2) proibições de retirar madeira do PEMA. Apenas 18,9\% dos entrevistados afirmaram que o Parque tem alguns benefícios, como a (1) preservação das pinturas rupestres; (2) a conservação dos animais; (3) e a atração de turistas para a região. 


\section{CONSIDERAÇÕES FINAIS}

A maior parte das áreas ainda preservadas do território amazônico é habitada por populações indígenas ou por comunidades rurais, sejam elas caiçaras, ribeirinhas, seringueiras, quilombolas etc. Dessa maneira, a criação de unidades de conservação (UCs) na Amazônia, sobretudo as de proteção integral (que impõem medidas restritivas mais drásticas às populações locais), inevitavelmente gera conflitos entre os atores relacionados à problemática.

Este artigo buscou trazer contribuições à discussão sobre conflitos em UCs, a partir do estudo de caso do Parque Estadual Monte Alegre (PEMA), situado na porção noroeste do estado do Pará, Brasil. Criado em 2001, com objetivo principal de proteger as pinturas rupestres da área, o PEMA é um exemplo típico dos conflitos advindos da criação de UCs na região amazônica. A pesquisa teve como foco os conflitos envolvendo as populações ribeirinhas de Lages, Paituna e Santana, provocados pela criação do Parque.

Para atingir tal objetivo, o estudo se remeteu ao conceito de conflito desenvolvido por Simmel. Para o autor, há positividade nos conflitos. Estes são vistos como elementos vitais para a renovação e unidade das sociedades. Dessa maneira, à luz de Simmel, o estudo considerou os conflitos como instrumentos de transformação da realidade. Os conflitos entre os atores ligados à temática do PEMA foram aqui entendidos como essenciais para alterar o atual cenário de suspensão de direitos a que estão submetidas as comunidades estudadas. Além de Simmel, este trabalho utilizou a teoria social de Bourdieu para interpretar os conflitos gerados pela criação de UCs.

$\mathrm{O}$ artigo demonstrou que a criação do PEMA, ao restringir o uso dos recursos naturais, atingiu desfavoravelmente as atividades desenvolvidas pelas comunidades de Lages, Paituna e Santana. Isto desencadeou conflitos entre a instituição responsável pela gestão do Parque (SEMA ESTADUAL-PA) e os moradores locais. $O$ estudo constatou mudanças significativas no modo de vida dos ribeirinhos. As alterações ocorreram, sobretudo, nas atividades agrícolas e criatórias. A comunidade mais prejudicada foi a de Lages, que está situada inteiramente no interior do Parque. Assim, com a criação do PEMA, muitas famílias deixaram de plantar feijão e mandioca no local. Segundo relatos, a necessidade de comprar tais gêneros alimentícios diminuiu o orçamento das famílias visitadas.

A saída mais provável para a questão é a proposta de um Anteprojeto de Lei que altera a área e o perímetro do PEMA e a área da APA Paytuna. O objetivo do Anteprojeto é perimir que as populações ribeirinhas de Lages continuem na 
área onde moram há anos, por meio da retificação dos limites do Parque. Porém, tal Anteprojeto é ainda uma ideia e não foi encaminhado para a Assembleia Legislativa do estado do Pará.

Esta medida (Anteprojeto) está longe de ser ideal. Conforme foi dito, Lages encontra-se na situação mais delicada, uma vez que está totalmente inserida no Parque. No entanto, várias famílias das outras comunidades detêm posses dentro dos limites do PEMA. Estas perderam parte de suas terras, a saber, os fundos dos estabelecimentos rurais.

Por fim, destaca-se que as necessidades de exploração dos recursos naturais das comunidades de Lages, Paituna e Santana devem ser reconhecidas. O que atualmente ocorre é a criminalização dos atos mais corriqueiros e fundamentais para a reprodução sociocultural dessas comunidades. A caça, a pesca, a utilização de recursos da floresta para a manufatura de utensílios e equipamentos diversos, a feitura das roças, a criação de galinhas ou porcos, a lenha para cozinhar e aquecer, a construção de uma nova casa para o filho que se casou etc. - tudo foi transformado em crime.

Para concluir, cabe perguntar: como obrigar as populações ribeirinhas a abrir mão do uso dos recursos naturais (necessários para sua subsistência) em prol da preservação do meio ambiente? Em algum momento, a causa ambientalista considerou como natural impedir que certas populações usufruam de seu meio para promover atividades econômicas que gerem riquezas e melhorem suas condições de vida. Porém, sabe-se agora que não se trata de evitar que as populações que possuem territórios ainda preservados disponham de seu meio para obter maior bem-estar. O que se deve fazer é evitar que cometam os mesmos erros daqueles que obtiveram riquezas à custa de danos irreversíveis à natureza.

\section{REFERÊNCIAS}

ACSELRAD, H. Conflitos Ambientais: a atualidade do objeto. In: ACSELRAD, H. (Org.). Conflitos ambientais no Brasil. Rio de Janeiro: Relume Dumará; Fundação Heinrich Böll, 2004. p. 7-12.

ADAMS, C.; MURRIETA, R.; NEVES, W. Introdução - As sociedades caboclas amazônicas: modernidade e invisibilidade. In: ADAMS, C.; MURRIETA, R.; NEVES, W. (Orgs.). Sociedades caboclas amazônicas: modernidade e invisibilidade. São Paulo: Annablume, 2006. p. 15-32. 
ALENCAR, E. F. Políticas Públicas e (in)sustentabilidade social: o caso das comunidades de várzea no alto Solimões, Amazonas. In: LIMA, D. (Org.). Diversidade socioambiental nas várzeas dos rios Amazonas e Solimões: perspectivas para o desenvolvimento da sustentabilidade. Manaus: IBAMA, ProVárzea, 2005. p. 59-100.

AN-NA'IM, A.; PESHKOVA, S. Social movements revisited: mediation of contradictory roles. In: AMADIUME I.; AN-NA'IM, A. (Orgs.). The politics of memory. Truth, healing \& social justice. Londres: Zed Books, 2000. p. 68-89. ARON, R. As etapas do pensamento sociológico. São Paulo: Martins Fontes, 2003.

ARRUDA, R. S. V. "Populações Tradicionais" e a Proteção dos Recursos Naturais em Unidades de Conservação. In: DIEGUES, A. C. Etnoconservação: novos rumos para a proteção da natureza nos trópicos. São Paulo: HUCITEC, NUPAUB, 2000.

BARRETO, H. T. Da nação ao planeta através da natureza: uma tentativa de abordagem antropológica das unidades de conservação. Série Antropológica. Brasília, 1997.

BENSUSAN, N. Conservação da Biodiversidade em Áreas Protegidas. Rio de Janeiro: Editora FGV, 2006.

BOURDIEU, P. Questões de Sociologia. Rio de Janeiro: Marco Zero, 1983.

Razões Práticas: sobre a teoria da ação. Tradução: de Mariza Corrêa. Campinas; São Paulo: Papirus, 1996.

BRASIL. Ministério do Meio Ambiente. Plano de Manejo do Parque Estadual Monte Alegre. Belém, 2009.

BURSZTYN, M. Alguns temas da questão setentrional: uma contribuição ao debate sobre um projeto para a Amazônia. In: SAYAGO, D.; TOURRAND, J. F., M. Amazônia: Cenas e Cenários. Editora UnB. Brasília, 2004.

CONAN, M. A Natureza, a Religião e a identidade americana. In: BOURG, D. Os Sentimentos da Natureza. Lisboa: Instituto Piaget: 1993. p. 189-210.

DAVENPORT, L.; RAO, M. A história da proteção: paradoxos do passado e desafios do futuro. In: TERBORGH, J.; VAN SCHAIK, C.; DAVENPORT, L.; RAO, M. (Org.). Tornando os parques eficientes: estratégias para a conservação da natureza nos trópicos. Curitiba: UFPR; Fundação O Boticário, 2002. p. 52-73. 
DESCOLA, P. Ecologia e Cosmologia. In: DIEGUES, A. C. Etnoconservação: novos rumos para a proteção da natureza nos trópicos. São Paulo: HUCITEC, NUPAUB-USP, 2000.

DIEGUES, A. C. Etnoconservação da Natureza: Enfoques Alternativos. In: DIEGUES, A. C. Etnoconservação: novos rumos para a proteção da natureza nos trópicos. São Paulo: HUCITEC; NUPAUB-USP, 2000.

O mito moderno da natureza intocada. São Paulo: HUCITEC; NAPAUB, USP, 1994.

DRUMMOND, J. A.; FRANCO, J. L. A.; NINIS, A. B. O Estado das Áreas Protegidas no Brasil. Brasília, agosto de 2006. Disponível em: <http://www. unbcds.pro.br /conteudo_arquivo/150607_2F62A6.pdf >. Acesso em: 26 nov. 2010.

DURKHEIM, E. O Suicídio: estudo de sociologia. São Paulo: Martins Fontes, 2000 .

LEDERACH, J. P. Conflict Transformation in Protracted Internal Conflicts: The Case for a Comprehensive Network. In: RUPESINGHE, K. (Ed.). Conflict Transformation. New York: St. Martin's Press, 1995.

LITTLE, P. E. A etnografia dos conflitos sócio-ambientais: bases metodológicas e empíricas. In: I ENCONTRO DA ASSOCIAÇÃO NACIONAL DE PÓSGRADUAÇÃO E PESQUISA EM AMBIENTE E SOCIEDADE - ANPPAS, 2004. Indaiatuba. Anais... Indaiatuba, 2004.

Os Conflitos Socioambientais: um campo de estudo e de ação política. In: BURSZTYN, M. (Org.). A difícil sustentabilidade: política energética e conflitos ambientais. Rio de Janeiro: Garamond, 2001.

MERTON, R. Sociologia: teoria e estrutura. São Paulo: Mestre Jou, 1970.

NASCIMENTO, E. P. Os conflitos na sociedade moderna: uma introdução conceitual. In: BURSZTYN. M. (Org.) A difícil sustentabilidade: política energética e conflitos ambientais. Garamond, Rio de Janeiro, 2001. p. 85-106.

OLIVEIRA, S. A releitura dos critérios de justiça na região dos Lagos do Rio de Janeiro. In: ACSELRAD, H. (Org.). Conflitos ambientais no Brasil. Rio de Janeiro: Relume Dumará: Fundação Heinrich Böll, 2004. p. 95-130.

PÁDUA, M. T. J. Unidades de Conservação: muito mais do que atos de Criação e Planos de Manejo. In: MILANO, M. S. (org.). Unidades de Conservação: atualidades e tendências. Curitiba: Fundação. O Boticário de Proteção à natureza, 2002. p. 3-13.

Novos Cadernos NAEA • v. 15 n. $2 \cdot$ p. 21-44 • dez. 2012 
PANTOJA, M. C. A várzea do médio amazonas e a sustentabilidade de um modo de vida. In: LIMA, D. (Org.). Diversidade socioambiental nas várzeas dos rios Amazonas e Solimões: perspectivas para o desenvolvimento da sustentabilidade. Manaus: IBAMA, ProVárzea, 2005. p. 157-206.

PARETO, V. Vilfredo Pareto: Sociologia. São Paulo: Ática, 1984.

PARSONS, T. The social System. Nova York: Free Press, 1979.

PEREIRA, E. Arte Rupestre na Amazônia - Pará. Belém: Museu Paraense Emílio Goeldi; São Paulo: UNESP, 2003.

PNUD. Projeto de Assistência Preparatória para a Implementação da fase I do PROECOTUR. Brasília, 1999.

SEGATO, R. Antropologia e direitos humanos: alteridade e ética no movimento de expansão dos direitos universais. Mana. v. 12, n 1, 2006.

SILVA, R. O. Biodiversidade e políticas de conservação: o caso do Parque Estadual Monte Alegre - Pará. 1988. Tese (Doutorado em Desenvolvimento Sustentável) - Centro de Desenvolvimento Sustentável, Universidade de Brasília. Brasília, 2008.

SIMMEL, G. Georg Simmel: sociologia. São Paulo: Ática, 1983.

El conflito: sociología del antagonismo. Madri: Ediciones sequitur, 2010.

THOMAS, K. O homem e o mundo natural: mudanças de atitudes em relação às plantas e aos animais. São Paulo: Companhia de Letras, 1988.

VÄYRYNEN, R. From Conflict Resolution to Conflict Transformation: a critical view. In: HO-WON JEONG (Ed.). The New Agenda for Peace Research. Brookfield: Ashgate Publishing, 1999.

R. To Settle or to Transform? Perspectives on the Resolution of National and International Conflicts. In: VÄYRYNEN, R. (Ed.). New Directions in Conflict Theory: Conflict Resolution and Conflict Transformation. London: Sage, 1991. 


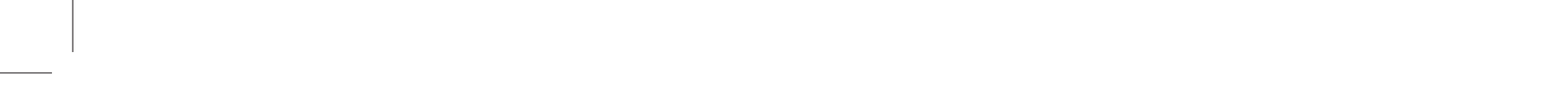

